\title{
Factorial Design Applied for Evaluation of Effect of Interactions among Precursors on the Thermal Decomposition Temperature of Montmorillonite/Poly(Methyl Methacrylate) Nanocomposites
}

\author{
Joseane A. Santana, ${ }^{a}$ Rennan G. O. Araujo, ${ }^{*, b}$ Filipe A. de Jesus, ${ }^{a}$ Kelly S. Lima, ${ }^{a}$ \\ Giovanna Machado, ${ }^{c}$ Maria C. P. Cruz $z^{a}$ and Victor H. V. Sarmento ${ }^{a}$ \\ ${ }^{a}$ Departamento de Química, Universidade Federal de Sergipe, Campus Professor Alberto Carvalho, \\ Av. Vereador Olimpio Grande, s/n, 49500-000 Itabaiana-SE, Brazil \\ ${ }^{b}$ Departamento de Química Analítica, Instituto de Química, Universidade Federal da Bahia, \\ Campus Universitário Ondina, Rua Jeremoabo, 147, 40170-115 Salvador-BA, Brazil \\ ${ }^{c}$ Centro de Tecnologias Estratégicas do Nordeste, Av. Prof. Luís Freire, 1, Cidade Universitária, \\ 50740-540 Recife-PE, Brazil
}

\begin{abstract}
In this work, full $2^{4}$ factorial design with triplicate of the central points was used to study the effect of synthesis conditions on the temperature of thermal decomposition $\left(\mathrm{T}_{\mathrm{d}}\right)$ of protonated montmorillonite/poly(methyl methacrylate) $\left(\mathrm{H}^{+} \mathrm{Mt} / \mathrm{PMMA}\right.$ ) nanocomposites. From combination of the independent variables such as polymer (methyl methacrylate, MMA), coupling agent (3-(trimethoxysilyl)propyl methacrylate, TMSM), thermal polymerizing initiator (benzoyl peroxide, BPO) and clay based on protonated montmorillonite $\left(\mathrm{H}^{+} \mathrm{Mt}\right), 19$ samples were prepared and $\mathrm{T}_{\mathrm{d}}$ was obtained by thermogravimetry $(\mathrm{TG}) . \mathrm{T}_{\mathrm{d}}$ values were statistically analyzed and the results presented that the sample prepared by combination of $150 \mathrm{mmol}$ of MMA, $23 \mathrm{mmol}$ TMSM, $0.186 \mathrm{mmol}$ $\mathrm{BPO}$ and $0.150 \mathrm{~g} \mathrm{H}^{+} \mathrm{Mt}$ (named experiment 7 ) presented the highest $\mathrm{T}_{\mathrm{d}}$ value $\left(381{ }^{\circ} \mathrm{C}\right.$ ). It was also possible to notice that the maximization/minimization of $\mathrm{T}_{\mathrm{d}}$ value is tunable in function of experimental conditions employed in the synthesis process. Partial compatibilization between PMMA and $\mathrm{H}^{+}$Mt was noticed through structural (Fourier transform infrared (FTIR)) and morphological (transmission electron microscope (TEM)) characterizations.
\end{abstract}

Keywords: nanocomposites, PMMA, $\mathrm{H}^{+} \mathrm{Mt}$, factorial design, temperature of thermal decomposition

\section{Introduction}

Since the first report from the Toyota research group, ${ }^{1}$ studies about clay/polymer nanocomposites (CPN) have been attracting more attention because they allow to understand the factors involved on the determination of its structural properties. These materials present physical and chemical characteristics different from those of neat polymer matrix, which makes possible its application as flame retardant, ${ }^{2,3}$ gas diffusion barrier, ${ }^{4}$ advanced anti-corrosion coatings, $, 5,6$ and materials with high solvent resistance or improved thermal properties. ${ }^{7-10}$

CPN preparation demands compatibility between the polymer and the clay, which require the utilization of organophilic clays or compatibilizers (bifunctional

*e-mail: rgoa01@terra.com.br, rennan@ufba.br molecules that conjugate an organic and an inorganic moiety, as organically modified silicates (ORMOSIL's)). ${ }^{8,11,12}$ Thus, several kinds of polymerization processes can be employed, as in situ, by solution, by emulsion and by suspension. ${ }^{13}$

Poly(methyl methacrylate) (PMMA) is a widely employed polymer of methacrylate class that presents as main characteristics its transparency (light transmission rate of $92 \%),{ }^{14,15}$ good resistance to electricity, corrosion and atmospheric agents, ${ }^{16-18}$ glass-like aspect and easy processability. ${ }^{19,20}$ As a drawback, polymeric materials as PMMA presents low thermal resistance, which makes necessary the addition of ceramic materials, as clays, to increase the thermal stability when some applications are targeted. ${ }^{2,3}$

Since the pioneering study reported by Blumstein, ${ }^{21}$ several research works confirmed the improvement of thermal stability of CPN compared to pristine polymer. ${ }^{22,23}$ 
Utilization of montmorillonite (Mt) with PMMA is widely reported in the literature, ${ }^{24,25}$ however, the focus is on the usage of organophilic clays, usually treated with ammonium quaternary salts. This choice facilitates the interaction between the polymer network and the clay, which results in better clay dispersion and, consequently, in materials with improved properties. On the other hand, to the best of our knowledge, there is a lack of studies about the use of the acid specie of $\mathrm{Mt}\left(\mathrm{H}^{+} \mathrm{Mt}\right)$ with the same purpose. $\mathrm{H}^{+} \mathrm{Mt}$ is an acid clay usually applied to polymerization of unsaturated hydrocarbons, ${ }^{26}$ biodiesel production, ${ }^{27}$ removal of dyes on vegetal oil industries ${ }^{28}$ and oil adsorbent in water. ${ }^{29} \mathrm{H}^{+} \mathrm{Mt}$ from Sigma-Aldrich has a surface area of $20-40 \mathrm{~m}^{2} \mathrm{~g}^{-1}$ and due to absence of organophilic groups in $\mathrm{H}^{+}$Mt structure, its application to $\mathrm{CPN}$ synthesis requires the utilization of an organic-inorganic coupling agent, which should present suitable groups to bond organic polymer networks to clay structure. ORMOSIL's, as 3-(trimethoxysilyl)propyl methacrylate (TMSM), can play this role, once they have the required features.

It is known that the presence of the clay promotes changes on the thermal behavior of polymers due to changes in molecular dynamics of polymeric chains. However, the influence of the interaction between the components of the system (polymer, clay, coupling agents, surfactants) on the thermal properties is underexplored. This can be evaluated by multivariable factorial design.

Multivariable factorial design is a more reliable and refined approach to study CPNs because it allows to evaluate the effect of experimental variables, its interactions and estimates the optimal experimental conditions. ${ }^{30-32}$ This method is already widely employed in studies of different areas, like chemistry, ${ }^{30}$ materials science, ${ }^{31}$ medicine and pharmacy. ${ }^{33,34}$ Nevertheless, most works about preparation and/or properties of CPN employ univariate analysis. ${ }^{10-12}$

In this context, the present work aims to analyze, by full factorial design, the effects of different amounts of precursors (polymer, clay, coupling agent and thermal polymerizing initiator) and its possible interactions on the temperature of thermal degradation $\left(\mathrm{T}_{\mathrm{d}}\right)$ of $\mathrm{H}^{+} \mathrm{Mt} / \mathrm{PMMA}$ nanocomposites.

\section{Experimental}

\section{Materials and methods}

Precursors

$\mathrm{KSF}^{\circledR}$ montmorillonite ( $\mathrm{H}^{+} \mathrm{Mt}$, Sigma-Aldrich), 3-(trimethoxysilyl)propyl methacrylate (TMSM, 98\%, Sigma-Aldrich) and benzoyl peroxide (BPO, 75\%, Vetec), were analytical grade and used as received.
Methyl methacrylate (MMA, 98\%, Neon) was distilled, under atmospheric pressure, to remove hydroquinone (polymerization inhibitor) and stored in a freezer prior to usage. Tetrahydrofuran (THF, 99.70\%, Neon) was dried over sodium sulfate $\left(\mathrm{Na}_{2} \mathrm{SO}_{4}, 99 \%\right.$, Neon) and filtered.

\section{$\mathrm{H}^{+}$Mt/PMMA nanocomposites synthesis via in situ polymerization}

Experimental procedure consisted of two steps. At first, suitable amounts of MMA and $\mathrm{H}^{+} \mathrm{Mt}$ were mixed in a vial tube and the mixture was sonicated in an ultrasound bath, with frequency of $40 \mathrm{~Hz}$, for $3 \mathrm{~h}$. After sonication, MMA and $\mathrm{H}^{+} \mathrm{Mt}$ were stirred for $24 \mathrm{~h}$. At second step, appropriate amounts of BPO (polymerization initiator) and TMSM (coupling agent) were added to the vial, whose content was transferred to a flask with $130 \mathrm{~mL}$ of THF (solvent). The system was kept under reflux at $68^{\circ} \mathrm{C}$ for $24 \mathrm{~h}$. At the end, the final solution was poured in a polytetrafluoroethylene (PTFE) plate to obtain the nanocomposite films.

\section{Thermogravimetric analysis}

Thermogravimetry (TG) was utilized to evaluate thermal stability and obtain $\mathrm{T}_{\mathrm{d}}$ of the nanocomposites. TG curves were acquired on a TGA Q50 thermobalance (TA Instruments) in a dynamic argon atmosphere with $60 \mathrm{~mL} \mathrm{~min}{ }^{-1}$ flow and heating rate of $10{ }^{\circ} \mathrm{C} \mathrm{min}-1$ from room temperature to $600{ }^{\circ} \mathrm{C}$. Analyses were performed with about $7 \mathrm{mg}$ of film sample in platinum pans. Derivative thermogravimetric (DTG) curves were used to analyze thermal events more accurately, however, some thermal events were still overlapped. So, Origin $9.0^{\circledR}$ software $^{35}$ was utilized to decompose DTG thermal events in its components.

\section{Factorial design}

A full $2^{4}$ factorial design with triplicate of central points was used to evaluate the effects of MMA, TMSM, BPO and $\mathrm{H}^{+} \mathrm{Mt}$ amounts on $\mathrm{T}_{\mathrm{d}}$. Statistical data treatment was performed by Statistica 8.0 software $\left(\right.$ StatSoft $\left.^{\circledR}\right) .{ }^{36}$ The independent variables and its levels are presented in Table 1.

Table 1. Values of the variables studied using the full $2^{4}$ factorial design with triplicate of the central point with the system in an inert environment

\begin{tabular}{lccc}
\hline $\begin{array}{l}\text { Independent } \\
\text { variable }\end{array}$ & $\begin{array}{c}\text { Minimum } \\
(-1)\end{array}$ & $\begin{array}{c}\text { Central point } \\
(0)\end{array}$ & $\begin{array}{c}\text { Maximum } \\
(+1)\end{array}$ \\
\hline MMA / mmol & 150 & 180 & 210 \\
$\mathrm{TMSM} / \mathrm{mmol}$ & 15 & 19 & 23 \\
$\mathrm{BPO} / \mathrm{mmol}$ & 0.103 & 0.144 & 0.186 \\
$\mathrm{H}^{+} \mathrm{Mt} / \mathrm{g}$ & 0.150 & 0.300 & 0.450
\end{tabular}

MMA: methyl methacrylate; TMSM: 3-(trimethoxysilyl)propyl methacrylate; BPO: benzoyl peroxide; $\mathrm{H}^{+} \mathrm{Mt}: \mathrm{KSF}^{\circledR}$ montmorillonite. 


\section{Infrared spectroscopy}

In order to analyze samples structure, Fourier transform infrared spectroscopy (FTIR) was utilized. FTIR spectra were acquired in an IR Prestige-21 spectrometer (Shimadzu), in transmittance mode and in the range between 4000 and $400 \mathrm{~cm}^{-1}$ with $4 \mathrm{~cm}^{-1}$ resolution.

\section{Transmission electron microscopy (TEM)}

Aiming to obtain high-quality TEM images, CPN films were finely cut, embedded in an epoxy resin and the mold were treated in an oven at $60{ }^{\circ} \mathrm{C}$ for $48 \mathrm{~h}$. After treatment, samples were trimmed in trapeze shape to be sectioned with diamond razor $\left(35^{\circ} \mathrm{C}\right)$ in EM UC 6.0 (LEICA) cryogenic ultramicrotome, sliced in $90 \mathrm{~nm}$ thickness pieces with $10-30 \mathrm{~mm} \mathrm{~s}^{-1}$ rate and, finally, poured on 200 mesh copper grids. Then, TEM images were registered in Tecnai ${ }^{\mathrm{TM}} \mathrm{G} 2$ Spirit TWIN (FEI Company) microscope with acceleration tension of $100 \mathrm{kV}$.

\section{Results and Discussion}

\section{Thermal and statistical analysis}

The experiments performed with combination of the independent variables resulted in the preparation of 19 samples, named S1 to S19. The matrix of the full $2^{4}$ factorial design with triplicate of the central points is presented in Table 2. $\mathrm{T}_{\mathrm{d}}$ values, utilized as dependent variable, were obtained from TG analysis and are also presented.

It is noticeable that experimental conditions play an important role in the response variable result, which varies from 352 to $381{ }^{\circ} \mathrm{C}$. It is also possible to see in Table 2 that there is not simple patterns of $T_{d}$ variation, what is an indicative of interactions between independent variables.

TG and DTG curves (not totally showed) of $\mathrm{H}^{+} \mathrm{Mt} / \mathrm{PMMA}$ nanocomposite samples presented different shapes, which is attributed to different compositions related to its factorial design levels. So, the curves were gathered according to its profiles and number of thermal events, resulting in three groups represented in Figure 1 by S1, S11 and S14 samples.

Figure 1a presents TG curves of S1, S11 and S14 samples, in which significant profile changes can be observed. It is possible to notice similar thermal stabilities of samples in the range between room temperature and around $150{ }^{\circ} \mathrm{C}$. After this point, $\mathrm{S} 14$ sample is decomposed in a faster process than $\mathrm{S} 1$ and $\mathrm{S} 11$, whose degradation is initiated at higher temperatures. From 200 to about $500^{\circ} \mathrm{C}$ all samples presented a large mass loss process, which is stabilized between 500 and $600{ }^{\circ} \mathrm{C}$. At the end of the analysis it was obtained a residue with char aspect, whose mass percentage

Table 2. Matrix of the full $2^{4}$ factorial design with triplicate of the central point presenting $\mathrm{T}_{\mathrm{d}}$ values obtained from experiments 1 to 19 . Real and coded values

\begin{tabular}{|c|c|c|c|c|c|c|}
\hline Experiment & MMA / mmol & TMSM / mmol & $\mathrm{BPO} / \mathrm{mmol}$ & $\mathrm{H}^{+} \mathrm{Mt} / \mathrm{g}$ & Sample & $\mathrm{T}_{\mathrm{d}} /{ }^{\circ} \mathrm{C}$ \\
\hline 1 & $150(-1)$ & $15(-1)$ & $0.103(-1)$ & $0.150(-1)$ & S1 & 360 \\
\hline 2 & $210(+1)$ & $15(-1)$ & $0.103(-1)$ & $0.150(-1)$ & S2 & 358 \\
\hline 3 & $150(-1)$ & $23(+1)$ & $0.103(-1)$ & $0.150(-1)$ & S3 & 356 \\
\hline 4 & $210(+1)$ & $23(+1)$ & $0.103(-1)$ & $0.150(-1)$ & S4 & 356 \\
\hline 5 & $150(-1)$ & $15(-1)$ & $0.186(+1)$ & $0.150(-1)$ & S5 & 360 \\
\hline 6 & $210(+1)$ & $15(-1)$ & $0.186(+1)$ & $0.150(-1)$ & S6 & 368 \\
\hline 7 & $150(-1)$ & $23(+1)$ & $0.186(+1)$ & $0.150(-1)$ & S7 & 381 \\
\hline 8 & $210(+1)$ & $23(+1)$ & $0.186(+1)$ & $0.150(-1)$ & S8 & 353 \\
\hline 9 & $150(-1)$ & $15(-1)$ & $0.103(-1)$ & $0.450(+1)$ & S9 & 369 \\
\hline 10 & $210(+1)$ & $15(-1)$ & $0.103(-1)$ & $0.450(+1)$ & S10 & 352 \\
\hline 11 & $150(-1)$ & $23(+1)$ & $0.103(-1)$ & $0.450(+1)$ & S11 & 378 \\
\hline 12 & $210(+1)$ & $23(+1)$ & $0.103(-1)$ & $0.450(+1)$ & S12 & 367 \\
\hline 13 & $150(-1)$ & $15(-1)$ & $0.186(+1)$ & $0.450(+1)$ & S13 & 359 \\
\hline 14 & $210(+1)$ & $15(-1)$ & $0.186(+1)$ & $0.450(+1)$ & S14 & 378 \\
\hline 15 & $150(-1)$ & $23(+1)$ & $0.186(+1)$ & $0.450(+1)$ & S15 & 359 \\
\hline 16 & $210(+1)$ & $23(+1)$ & $0.186(+1)$ & $0.450(+1)$ & S16 & 369 \\
\hline 17 & $180(0)$ & $19(0)$ & $0.144(0)$ & $0.300(0)$ & S17 & 366 \\
\hline 18 & $180(0)$ & $19(0)$ & $0.144(0)$ & $0.300(0)$ & S18 & 364 \\
\hline 19 & $180(0)$ & $19(0)$ & $0.144(0)$ & $0.300(0)$ & $\mathrm{S} 19$ & 361 \\
\hline
\end{tabular}

MMA: methyl methacrylate; TMSM: 3-(trimethoxysilyl)propyl methacrylate; BPO: benzoyl peroxide; $\mathrm{H}^{+}$Mt: KSF${ }^{\circledR}$ montmorillonite; $\mathrm{T}_{\mathrm{d}}$ : temperature of thermal decomposition. 
(a)

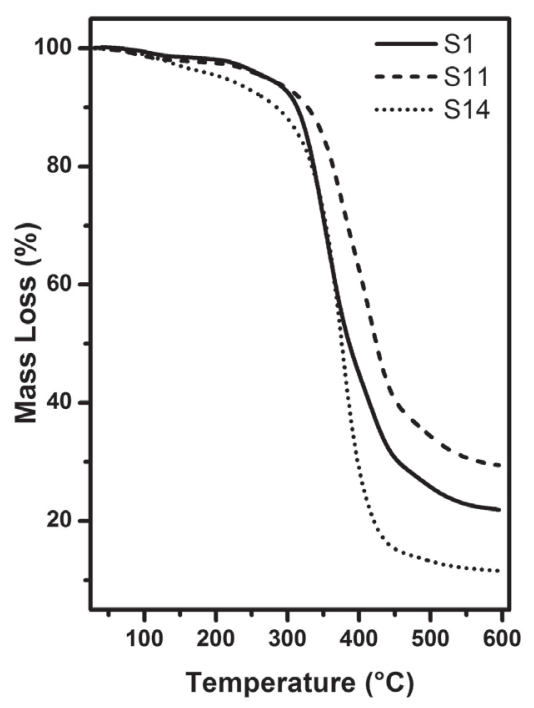

(b)

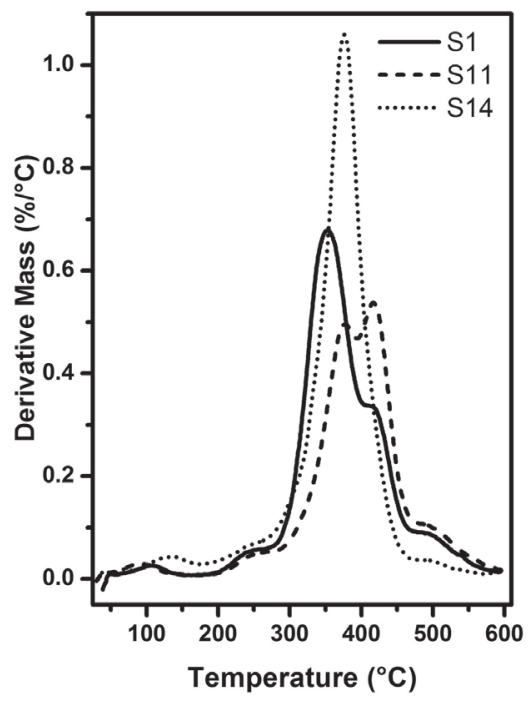

Figure 1. (a) TG and (b) DTG curves obtained for samples S1, S11 and S14 presenting different thermal degradation profiles.

varied from $11.5 \%$ for S14 to 21.9 and $29.4 \%$ to S1 and S11, respectively. These changes in residue percentage show that precursors amounts have great influence on the thermal behavior and stability of $\mathrm{H}^{+} \mathrm{Mt} / \mathrm{PMMA}$ nanocomposites, once that $\mathrm{S} 11$ presented a very larger temperature resistance than S14. Figure 1b presents DTG curves, which determines the number of thermal events occurring in each sample.

In order to make a more accurate analysis, DTG curve was fitted in order to separate overlapped peaks. Results are presented in Figure 2. Event parameters as temperature range $\left(\mathrm{T}_{\mathrm{R}}\right)$, temperature of maximum degradation rate $\left(\mathrm{T}_{\max }\right)$ and mass loss percentage $\left(\% \mathrm{M}_{\mathrm{L}}\right)$, obtained from suitable treatment of curves and calculations, are presented in Table 3 .

It is possible to associate the first thermal event of all DTG curves to removal of remaining solvent molecules (water and THF) and non-polymerized MMA monomers (boiling point about $100{ }^{\circ} \mathrm{C}$ ). Presence of these molecules in the films is showed in FTIR spectra (presented in next session) and is also reported by Carvalho et al., ${ }^{8,9}$ which suggest that is usual the presence of monomer molecules in the final system due to radical polymerization yield. In accordance with the studies of Kashiwagi et al., ${ }^{37,38}$ the second event of all samples, with $\mathrm{T}_{\max }$ between 248 and $270{ }^{\circ} \mathrm{C}$, can be assigned to degradation of PMMA chains with unsaturated ends. The events located at $310-500{ }^{\circ} \mathrm{C}$ are associated to random scissions whose curves profile vary with the sample,,$^{37,38}$ while the event above $500{ }^{\circ} \mathrm{C}$ is related to the dehydration of silanol ( $\mathrm{Si}-\mathrm{OH}$ ) groups..$^{39}$ In general, it is possible to affirm that $\mathrm{H}^{+} \mathrm{Mt} / \mathrm{PMMA}$ nanocomposites degradation process is similar to that of neat PMMA, which was extensively studied in literature. . $^{37,40,41}$
Table 3. Thermal event parameters obtained through DTG curve fitting and thermal events separation

\begin{tabular}{lcccc}
\hline Event & Parameter & $\mathrm{S} 1$ & $\mathrm{~S} 11$ & $\mathrm{~S} 14$ \\
\hline \multirow{3}{*}{$1^{\text {st }}$} & $\mathrm{T}_{\mathrm{R}} /{ }^{\circ} \mathrm{C}$ & $46-161$ & $32-161$ & $40-234$ \\
& $\mathrm{~T}_{\max } /{ }^{\circ} \mathrm{C}$ & 105 & 91 & 132 \\
& $\% \mathrm{M}_{\mathrm{L}} / \%$ & 1.2 & 1.6 & 3.2 \\
\hline \multirow{2}{*}{$2^{\text {nd }}$} & $\mathrm{T}_{\mathrm{R}} /{ }^{\circ} \mathrm{C}$ & $174-337$ & $169-373$ & $147-346$ \\
& $\mathrm{~T}_{\max } /{ }^{\circ} \mathrm{C}$ & 254 & 270 & 248 \\
& $\% \mathrm{M}_{\mathrm{L}} / \%$ & 3.9 & 4.5 & 5.2 \\
\hline \multirow{4}{*}{$3^{\text {rd }}$} & $\mathrm{T}_{\mathrm{R}} /{ }^{\circ} \mathrm{C}$ & $248-460$ & $257-511$ & $242-378$ \\
& $\mathrm{~T}_{\max } /{ }^{\circ} \mathrm{C}$ & 353 & 383 & 310 \\
& $\% \mathrm{M}_{\mathrm{L}} / \%$ & 50.6 & 44.5 & 7.2 \\
\hline \multirow{3}{*}{$4^{\text {th }}$} & $\mathrm{T}_{\mathrm{R}} /{ }^{\circ} \mathrm{C}$ & $352-488$ & $373-478$ & $278-473$ \\
& $\mathrm{~T}_{\max } /{ }^{\circ} \mathrm{C}$ & 420 & 426 & 376 \\
& $\% \mathrm{M}_{\mathrm{L}} / \%$ & 12.6 & 9.4 & 69.2 \\
\hline \multirow{2}{*}{$5^{\text {th }}$} & $\mathrm{T}_{\mathrm{R}} /{ }^{\circ} \mathrm{C}$ & $356-597$ & $350-594$ & $378-594$ \\
& $\mathrm{~T}_{\max } /{ }^{\circ} \mathrm{C}$ & 483 & 494 & 499 \\
& $\% \mathrm{M}_{\mathrm{L}} / \%$ & 9.8 & 10.6 & 3.7 \\
\hline
\end{tabular}

S1: S1 sample; S11: S11 sample; S14: S14 sample; $T_{R}$ : temperature range; $\mathrm{T}_{\max }$ : temperature of maximum decomposition rate; $\% \mathrm{M}_{\mathrm{L}}$ : mass loss percentage.

Considering the thermal degradation mechanisms exhibited by samples studied here, $\mathrm{T}_{\max }$ was adopted as a response variable $\left(\mathrm{T}_{\mathrm{d}}\right)$ to factorial design analysis, which allows evaluating the possible influences of precursors amounts on thermal degradation of the samples.

Figure 3 presents a Pareto chart of $\mathrm{T}_{\mathrm{d}}$ results, in which the probability value $(p)$, as known as confidence level, of 0.05 (95\% of confidence level) was used and 
(a)

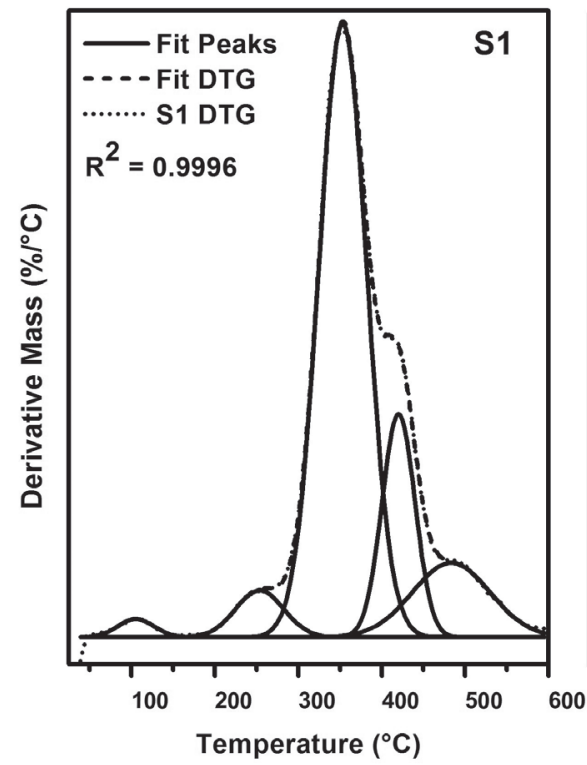

(b)

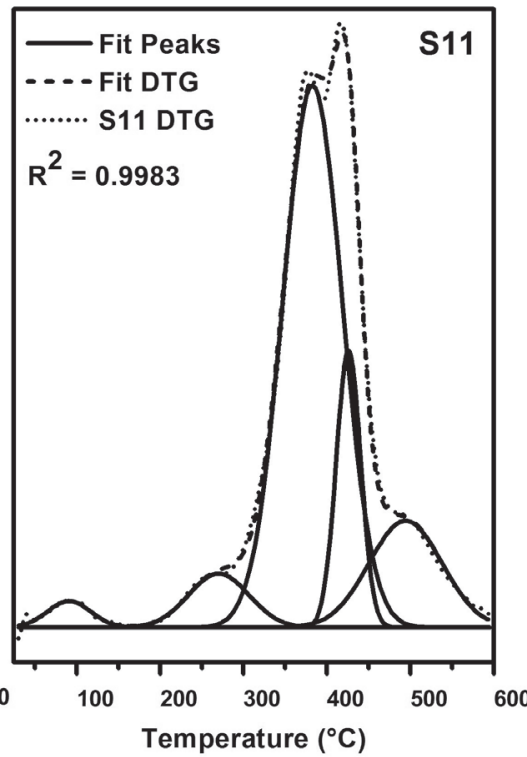

(c)

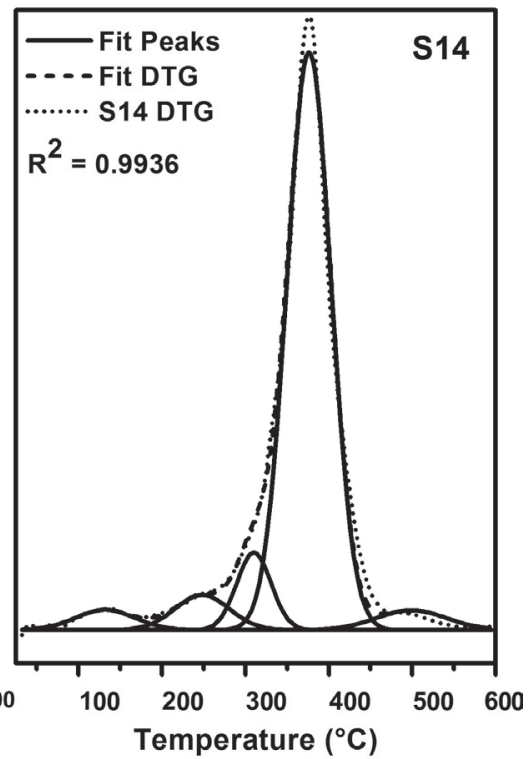

Figure 2. DTG curves analysis for samples (a) S1; (b) S11 and (c) S14: fit peaks (solid line), fit DTG (dashed black line) and sample DTG (dotted black line).

every effect after the line of this value was considered significant. ${ }^{42,43}$ This graph demonstrates that MMA, BPO, $\mathrm{H}^{+} \mathrm{Mt}$ and TMSM amounts are not major effects to $\mathrm{T}_{\mathrm{d}}$ variations, which also is valid to the second order variable interactions (when the effect of a variable depends on the level of another one). On the other hand, some third order variable interactions (when the effect of a variable depends on the level of two other) have important effects on results of the response variable. The interaction between MMA, BPO and $\mathrm{H}^{+}$Mt amounts $(1 * 3 * 4)$ maximizes $\mathrm{T}_{\mathrm{d}}$ values, while TMSM, BPO and $\mathrm{H}^{+}$Mt amounts $(2 * 3 * 4)$ and MMA, TMSM and BPO amounts $(1 * 2 * 3)$ decrease and minimize, respectively, the response variable results. In turn, the third order interaction between the variables

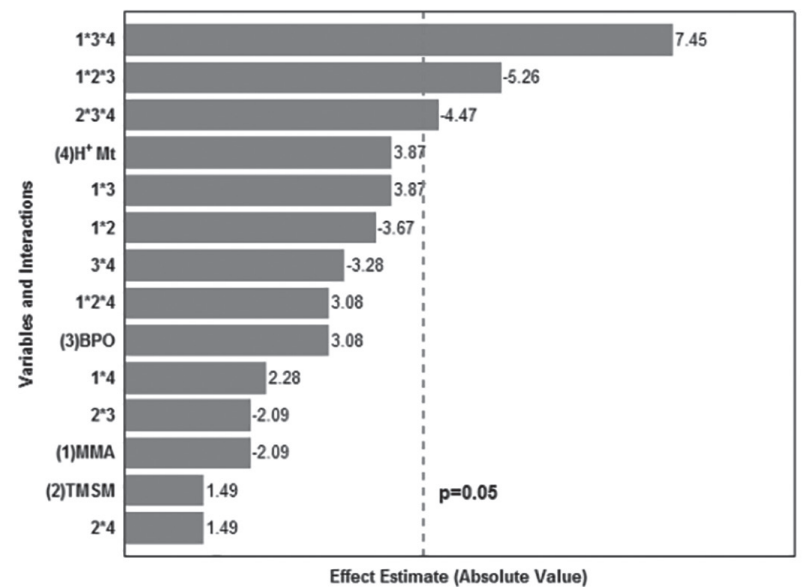

Figure 3. Pareto chart of the four standardized variables studied: (1) MMA amount (mmol); (2) TMSM amount (mmol); (3) BPO amount (mmol) and (4) $\mathrm{H}^{+}$Mt amount (g).
MMA*TMSM*H+ Mt amounts $(1 * 2 * 4)$ does not change significantly $\mathrm{T}_{\mathrm{d}}$ to the significance level of $95 \%$.

In order to evaluate if the obtained model can describe properly the system and to check the possibility of using this model to estimate the effects, coefficients and optimal region of the results, it was performed an analysis of variance (ANOVA). An ideal model must present a significant regression and an insignificant lack of fit, in other words, the biggest part of average deviations have been described by regression equation and the other part must be on the residues. It is still expected that most part of residues are in the naked error, which is referred to the experimental error and not to the lack of fit (directly related to the model). ${ }^{43}$

ANOVA results are displayed in Tables 4 and 5. Main interaction effect, coefficients of the model, standard deviation of each coefficient, and probability for the full factorial design with triplicate of central points of $\mathrm{T}_{\mathrm{d}}$. A linear fit model was utilized and presents suitable responses for prediction in the range of chosen variables, what configures it as a proper model. The significance of the regression coefficients was determined by applying a Student's $t$-test. Furthermore, the model presented a determination coefficient $\left(r^{2}\right)$ of 0.9641 , which is a good result. The function presented in equation 1 describes how the third-order interactions have significantly influenced the response variable $\left(T_{d}\right)$, considering a confidence level of $95 \%$.

$$
\begin{aligned}
& \mathrm{T}_{\mathrm{d}}=363.89-3.31(\mathrm{MMA} \times \mathrm{TMSM} \times \mathrm{BPO})+ \\
& 4.69\left(\mathrm{MMA} \times \mathrm{BPO} \times \mathrm{H}^{+} \mathrm{Mt}\right)- \\
& 2.81\left(\mathrm{TMSM} \times \mathrm{BPO} \times \mathrm{H}^{+} \mathrm{Mt}\right)
\end{aligned}
$$


Table 4. Estimated effects and coefficients for $T_{d}$

\begin{tabular}{|c|c|c|c|c|c|c|}
\hline Parameter & Effect & Coef & SE Coef & $\mathrm{T}$ & $p$ & Comment \\
\hline Mean & 363.89 & 363.89 & 0.58 & 630.28 & 0.00 & - \\
\hline (1) MMA / mmol & -2.62 & -1.31 & 1.26 & -2.09 & 0.17 & insignificant \\
\hline (2) $\mathrm{TMSM} / \mathrm{mmol}$ & 1.88 & 0.94 & 1.26 & 1.49 & 0.27 & insignificant \\
\hline (3) $\mathrm{BPO} / \mathrm{mmol}$ & 3.88 & 1.94 & 1.26 & 3.08 & 0.09 & insignificant \\
\hline (4) $\mathrm{H}^{+} \mathrm{Mt} / \mathrm{g}$ & 4.88 & 2.44 & 1.26 & 3.87 & 0.06 & insignificant \\
\hline $1 * 2$ & -4.63 & -2.31 & 1.26 & -3.68 & 0.07 & insignificant \\
\hline $1 * 3$ & 4.87 & 2.44 & 1.26 & 3.87 & 0.06 & insignificant \\
\hline $1 * 4$ & 2.88 & 1.44 & 1.26 & 2.28 & 0.15 & insignificant \\
\hline $2 * 3$ & -2.63 & -1.31 & 1.26 & -2.09 & 0.17 & insignificant \\
\hline $2 * 4$ & 1.88 & 0.94 & 1.26 & 1.49 & 0.27 & insignificant \\
\hline $3 * 4$ & -4.12 & -2.06 & 1.26 & -3.28 & 0.08 & insignificant \\
\hline $1 * 2 * 3$ & -6.63 & -3.31 & 1.26 & -5.27 & 0.03 & significant \\
\hline $1 * 2 * 4$ & 3.87 & 1.94 & 1.26 & 3.08 & 0.09 & insignificant \\
\hline $1 * 3 * 4$ & 9.37 & 4.69 & 1.26 & 7.45 & 0.02 & significant \\
\hline $2 * 3 * 4$ & -5.63 & -2.81 & 1.26 & -4.47 & 0.05 & significant \\
\hline
\end{tabular}

Coef: coefficient; SE Coef: standard error coefficient; T: $t$-value; $p$ : probability value; MMA: methyl methacrylate; TMSM: 3-(trimethoxysilyl)propyl methacrylate; BPO: benzoyl peroxide; $\mathrm{H}^{+} \mathrm{Mt}$ : $\mathrm{KSF}^{\circledR}$ montmorillonite.

Table 5. Results of the ANOVA

\begin{tabular}{|c|c|c|c|c|c|}
\hline Parameter & SS & $\mathrm{DF}$ & MS & $F$ & $p$ \\
\hline (1) MMA / mmol & 27.6 & 1 & 27.56 & 4.35 & 0.172 \\
\hline (2) TMSM / mmol & 14.1 & 1 & 14.06 & 2.22 & 0.275 \\
\hline (3) $\mathrm{BPO} / \mathrm{mmol}$ & 60.1 & 1 & 60.06 & 9.48 & 0.091 \\
\hline (4) $\mathrm{H}^{+} \mathrm{Mt} / \mathrm{g}$ & 95.1 & 1 & 95.06 & 15.01 & 0.061 \\
\hline $1 * 2$ & 85.6 & 1 & 85.56 & 13.51 & 0.067 \\
\hline $1 * 3$ & 95.1 & 1 & 95.06 & 15.01 & 0.061 \\
\hline $1 * 4$ & 33.1 & 1 & 33.06 & 5.22 & 0.150 \\
\hline $2 * 3$ & 27.6 & 1 & 27.56 & 4.35 & 0.172 \\
\hline $2 * 4$ & 14.1 & 1 & 14.06 & 2.22 & 0.275 \\
\hline $3 * 4$ & 68.1 & 1 & 68.06 & 10.75 & 0.082 \\
\hline $1 * 2 * 3$ & 175.6 & 1 & 175.56 & 27.72 & 0.034 \\
\hline $1 * 2 * 4$ & 60.1 & 1 & 60.06 & 9.48 & 0.091 \\
\hline $1 * 3 * 4$ & 351.6 & 1 & 351.56 & 55.51 & 0.018 \\
\hline $2 * 3 * 4$ & 126.6 & 1 & 126.56 & 19.98 & 0.047 \\
\hline Lack of fit & 33.2 & 2 & 16.62 & 2.62 & 0.276 \\
\hline Pure error & 12.67 & 2 & 6.33 & & \\
\hline Total SS & 1279.8 & 18 & & & \\
\hline
\end{tabular}

SS: sum of squares; DF: degree of freedom; MS: mean square; $F$ : $F$-value; $p$ : probability value; MMA: methyl methacrylate; TMSM: 3-(trimethoxysilyl) propyl methacrylate; BPO: benzoyl peroxide; $\mathrm{H}^{+} \mathrm{Mt}$ : $\mathrm{KSF}^{\circledast}$ montmorillonite.

Table 5 presents the sum of squares utilized to estimate the factors effects and the $F$-index. These effects were evaluated through $t$-test, the significance level obtained was $5 \%$ and the model regression was significant to the level of $95 \%$. The lack of fit was evaluated through the $F$-test, which determines that if the $F$-value obtained to a given effect is higher than the value of the theoretical $F$, this effect is significant. In this work, $F_{\text {calculated }}(2.62)$ was 
(a)

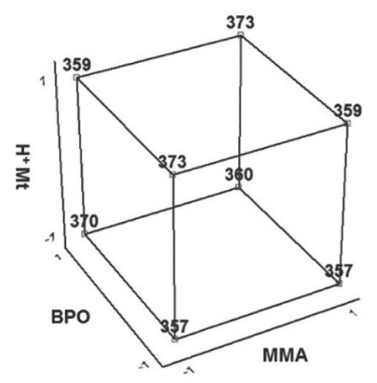

(b)

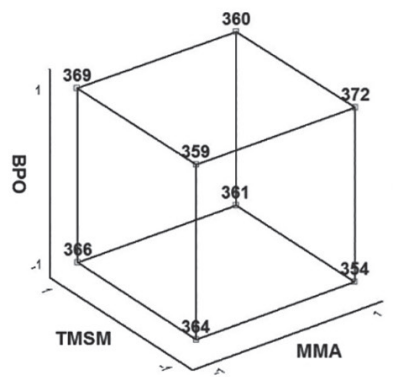

(c)

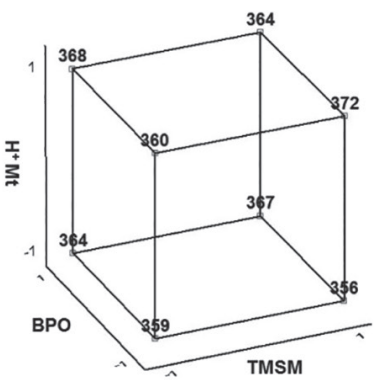

Figure 4. Geometric interpretation of the $\mathrm{T}_{\mathrm{d}}$ effects in full $2^{4}$ factorial design with triplicate of central points of the significant interactions: (a) MMA, BPO and $\mathrm{H}^{+} \mathrm{Mt}$; (b) MMA, TMSM and BPO; (c) TMSM, BPO and $\mathrm{H}^{+}$Mt.

lower than $F_{\text {tabulated }}(19.00)$, showing that there was no lack of fit ( $p$-value $=0.276$ ). The statistically obtained $\mathrm{r}^{2}$ value indicates that the first order model explained $96.41 \%$ of $\mathrm{T}_{\mathrm{d}}$ variations.

As discussed previously, the interactions between the variables MMA*BPO* $\mathrm{H}^{+} \mathrm{Mt}, \mathrm{MMA} * \mathrm{TMSM} * \mathrm{BPO}$ and $\mathrm{TMSM} * \mathrm{BPO} * \mathrm{H}^{+}$Mt amounts were statistically significant for temperature of thermal decomposition and its combinations are presented geometrically as a cube in Figure 4. The utilization of cubes is suitable to represent third order interactions and allows evaluating how significant is an effect compared to the others when independent variables levels are maximized or minimized.

In Figures $4 \mathrm{a}, 4 \mathrm{~b}$ and $4 \mathrm{c}$ it is possible to notice that the values presented in cube vertices are different from those showed in Table 2. This occurs because $T_{d}$ values were statistically treated for all possible combinations between these variables, so that results in the cube vertices are altered as combinations of -1 and +1 variables levels are performed.

The model evaluation was also performed by correlation of predicted and obtained values as presented in the correlation graph of Figure 5, which exhibits a very strong correlation coefficient $(r=0.9819)$ between the TG results and those predicted by full factorial design. ${ }^{44}$ After simultaneous analysis of the data, it was observed that the optimum conditions to maximize temperature of thermal decomposition are that of experiment 7. The combination of $150 \mathrm{mmol}$ of MMA, $23 \mathrm{mmol}$ TMSM, $0.186 \mathrm{mmol} \mathrm{BPO}$ and $0.150 \mathrm{~g} \mathrm{H}^{+}$Mt resulted in a $\mathrm{T}_{\mathrm{d}}$ of $381{ }^{\circ} \mathrm{C}$, being considered, therefore, the ideal condition to obtain nanocomposites with improved thermal properties.

\section{Structural and morphological characterization}

Figure 6 presents FTIR spectra of $\mathrm{H}^{+}$Mt clay, S1, S11 and S14 samples. The purpose of nanocomposite spectra is to prove the formation of PMMA-co-PTMSM

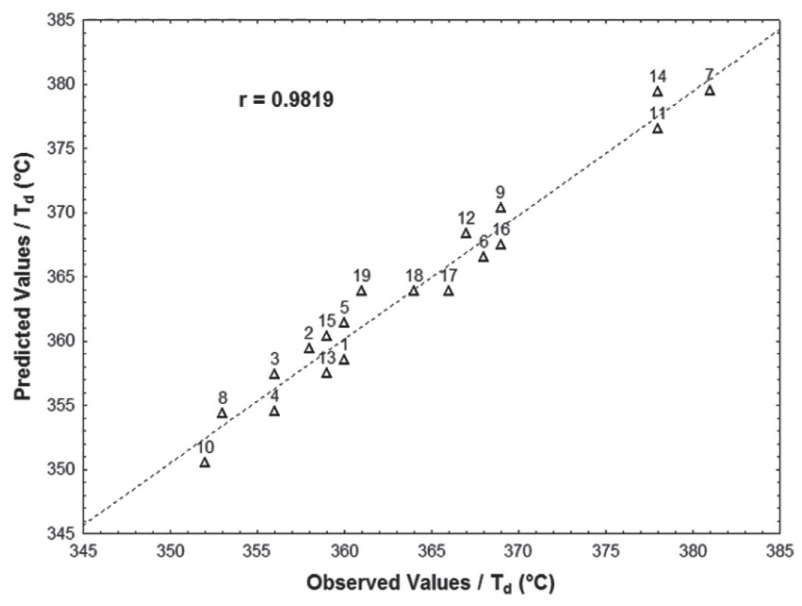

Figure 5. Correlation graph of $\mathrm{T}_{\mathrm{d}}$ values obtained from $\mathrm{TG}$ analysis and from modeling.

copolymer and to observe the presence of bands associated to a clay structure. Band attribution was made in the figure in accordance with Bieseki et al. ${ }^{45}$ for $\mathrm{H}^{+} \mathrm{Mt}$, and Namouchi et al. ${ }^{46}$ for nanocomposite samples. It can be observed in Figure 6 that all the spectra presented a wide band of about $3500 \mathrm{~cm}^{-1}$, which indicates the presence of free or weakly adsorbed water molecules. Bands at $1200-900$ and $500-400 \mathrm{~cm}^{-1}$ regions correspond to $\mathrm{Si}-\mathrm{O}$ bonds, both in clay and copolymer structure vibrations. At $\mathrm{H}^{+} \mathrm{Mt}$ spectrum (gray bottom line), a small shoulder at $3628 \mathrm{~cm}^{-1}$ can be seen which is related to the presence of free silanol $(\mathrm{Si}-\mathrm{OH})$ groups of lamellar structure.

At S1, S11 and S14 spectra, we observe that the majority of bands correspond to methacrylate structure, formed by MMA and TMSM. The band at $1156 \mathrm{~cm}^{-1}$ was attributed to $\mathrm{Si}-\mathrm{O}$ groups, which overlaps to $\mathrm{C}-\mathrm{O}$ stretching from acrylate groups. Bands at $1600-1750 \mathrm{~cm}^{-1}$ region, with maxima at $1719 \mathrm{~cm}^{-1}$, were also observed and characteristic of $\mathrm{C}=\mathrm{O}$. At $1252 \mathrm{~cm}^{-1}$, signals associated to $\mathrm{C}-\mathrm{C}-\mathrm{O}$ groups are present and indicate a certain degree of monomer polymerization. Furthermore, deformation of $\mathrm{C}=\mathrm{C}$ groups are represented by a band at $1639 \mathrm{~cm}^{-1}$, which 


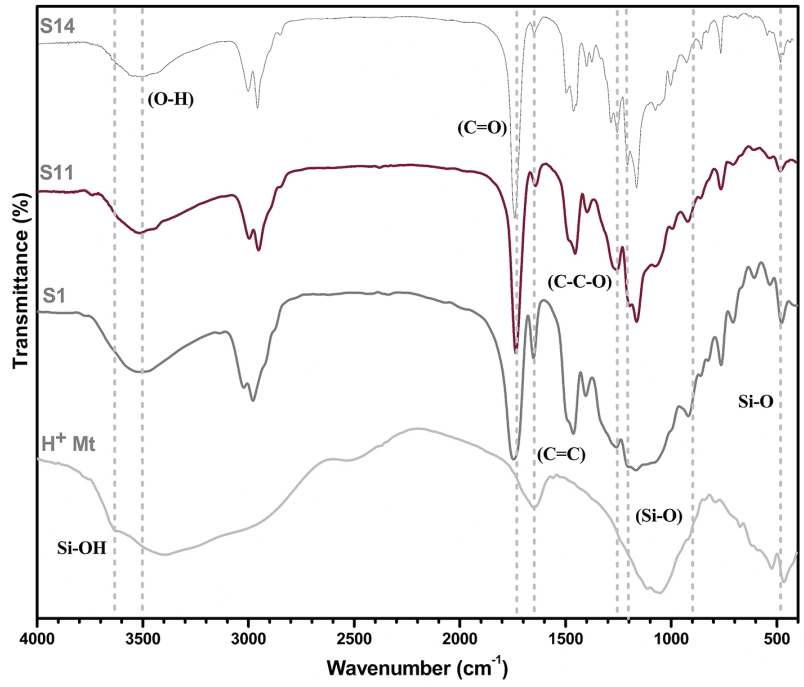

Figure 6. FTIR spectra of $\mathrm{H}^{+} \mathrm{Mt}, \mathrm{S} 1, \mathrm{~S} 11$ and $\mathrm{S} 14$ samples.

shows the presence of insaturation in nanocomposite polymer chains.

In general, FTIR spectra profiles were similar for all samples. Nevertheless, it was possible to notice some slight changes in the bands (position shifts, narrowing and broadening), which demonstrate the influence of different precursors combination on structural features of the nanocomposites. These results are in accordance with those of factorial design, which is of great relevance to prove the validity of the statistical approach used to study the system in question.

TEM is a widely employed technique in the study of nanostructures and it can help in the interpretation of results about the organization of clay layers on the nanocomposite. This technique enables the observation of nanostructures with excellent resolution. Figure 7 presents electronic microscopy images obtained for S1, S11 and S14 nanocomposites. In the images, bright regions associated to polymeric chains and dark regions, resulting from the coverslips of the clay (traces), can be seen.

There are points in which coverslips are apart from each other, however, clay dispersion in the polymeric matrix is not complete and agglomerates (sequenced tactoids) are present. It is not possible to affirm that there was basal increase in the clay in the nanocomposite samples, however, the materials presented a mixed, tactoid and exfoliated morphology. Even with a small clay content in the polymeric matrix, dispersion contributed to the increase in the thermal stability of nanocomposites.

Partial exfoliation of nanocomposites is a strong signal of MMA and $\mathrm{H}^{+}$Mt compatibilization promoted by TMSM. Carvalho et al. ${ }^{9}$ obtained the interlayered nanocomposites using TMSM as a compatibilizing agent for MMA and organophilic montmorillonite clay. (a)

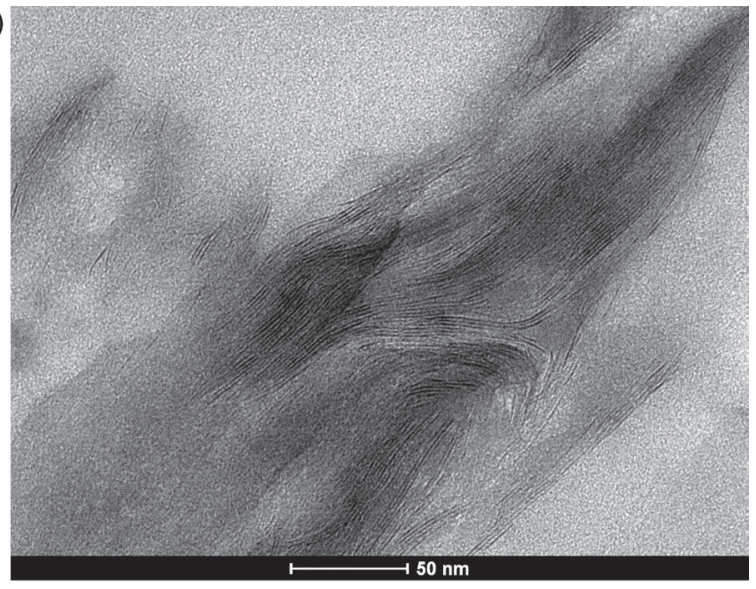

(b)

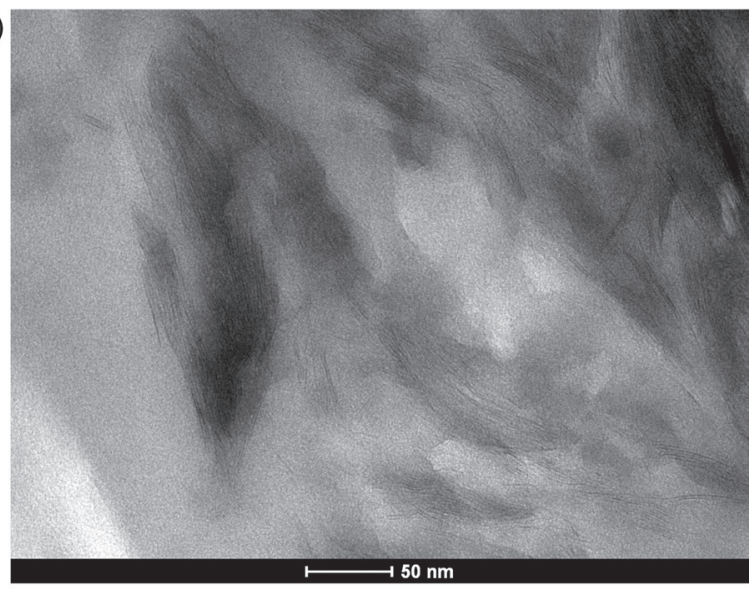

(c)

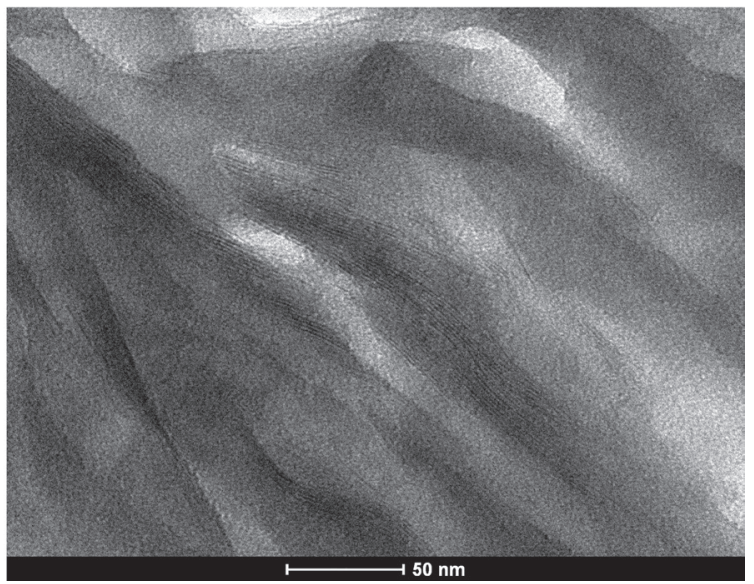

Figure 7. TEM images of (a) S1; (b) S11 and (c) S14 CPN samples.

However, there is no report in the literature of TMSM use for compatible acid $\mathrm{H}^{+}$Mt clay and MMA, which makes this study innovative.

\section{Conclusions}

It was possible, by utilization of full $2^{4}$ factorial design, to study the variables affecting $\mathrm{T}_{\mathrm{d}}$ values of $\mathrm{H}^{+} \mathrm{Mt} / \mathrm{PMMA}$ nanocomposites. With the study of these nanocomposites, it was possible to associate degradation events and thermal 
stability of the samples to the kind of polymeric networks formed. It reinforces the role of studying the amount of precursors in the composition of these materials, once that it has major influence on polymerization reactions.

The results presented that the only significant factors arise from third order interactions of independent variables, namely MMA/BPO/H $\mathrm{H}^{+} \mathrm{Mt}$, MMA/MPTS/BPO and $\mathrm{MPTS} / \mathrm{BPO} / \mathrm{H}^{+} \mathrm{Mt}$ amounts. This increase the importance of full $2^{4}$ factorial design to the context of this work, once that it would be impossible to identify these interactions without this tool. The analysis performed along the paper showed that the sample prepared by combination of $150 \mathrm{mmol}$ of MMA, $23 \mathrm{mmol}$ TMSM, $0.186 \mathrm{mmol} \mathrm{BPO}$ and $0.150 \mathrm{~g} \mathrm{H}^{+} \mathrm{Mt}$ (experiment 7) presented the highest $\mathrm{T}_{\mathrm{d}}$ value $\left(381^{\circ} \mathrm{C}\right)$, which makes it the ideal sample for future application tests. It was also possible to notice that the maximization/minimization of $T_{d}$ value is tunable in function of experimental conditions employed in the synthesis process. Morphological study have confirmed partial compatibilization of CPN samples through dispersion of copolymer chains on lamellar spaces of clays.

\section{Acknowledgments}

Authors would like to thank Prof Dr Ledjane Silva Barreto for providing $\mathrm{H}^{+} \mathrm{Mt}$ clay. The authors are also grateful to FAPITEC, CNPq, CETENE and FACEPE for providing grants, fellowships and for financial support.

\section{References}

1. Usuki, A.; Kojima, Y.; Kawasumi, M.; Okada, A.; Fukushima, Y.; Kurauchi, T.; Kamigaito, O.; J. Mater. Res. 1993, 8, 1179.

2. Sahoo, P. K.; Samal, R.; Polym. Degrad. Stab. 2007, 92, 1700.

3. Gilman, J.; Appl. Clay Sci. 1999, 15, 31.

4. Kalendova, A.; Merinska, D.; Gerard, J. F.; Slouf, M.; Polym. Compos. 2013, 34, 1418.

5. Chang, K.-C.; Chen, S.-T.; Lin, H.-F.; Lin, C.-Y.; Huang, H.-H.; Yeh, J.-M.; Yu, Y.-H.; Eur. Polym. J. 2008, 44, 13.

6. Wang, T.-L.; Hwang, W.-S.; Yeh, M.-H.; J. Appl. Polym. Sci. 2007, 104, 4135.

7. Huang, J.-C.; Zhu, Z.; Yin, J.; Qian, X.; Sun, Y.-Y.; Polymer 2001, 42, 873 .

8. Carvalho, H. W. P.; Santilli, C. V.; Briois, V.; Pulcinelli, S. H.; RSC Adv. 2013, 3, 22830.

9. Carvalho, H. W. P.; Suzana, A. F.; Santilli, C. V.; Pulcinelli, S. H.; Polym. Eng. Sci. 2013, 53, 1253.

10. Tsai, T. Y.; Lin, M. J.; Chuang, Y. C.; Chou, P. C.; Mater. Chem. Phys. 2013, 138, 230.

11. Huskić, M.; Žagar, E.; Žigon, M.; Eur. Polym. J. 2012, 48, 1555.

12. Meneghetti, P.; Qutubuddin, S.; Thermochim. Acta 2006, 442, 74.
13. Kickelbick, G.; Hybrid Materials: Synthesis, Characterization, and Applications; Kickelbick, G., ed.; Wiley-VCH: Weinheim, 2007, ch. 1.

14. Yeh, J. M.; Weng, C. J.; Liao, W. J.; Mau, Y. W.; Surf. Coat. Technol. 2006, 201, 1788.

15. Yamazaki, M.; J. Mol. Catal. A: Chem. 2004, 213, 81.

16. Messaddeq, S. H.; Pulcinelli, S. H.; Santilli, C. V.; Guastaldi, A. C.; Messaddeq, Y.; J. Non-Cryst. Solids 1999, 247, 164.

17. Zebarjad, S. M.; Engineering 2011, 03, 795.

18. Sanchez, C.; Julián, B.; Belleville, P.; Popall, M.;. J. Mater. Chem. 2005, 15, 3559.

19. Yu, Y.-Y.; Chen, W.-C.; Mater. Chem. Phys. 2003, 82, 388.

20. Bian, L.; Qian, X.; Yin, J.; Zhu, Z.; Lu, Q.; Mater. Sci. Eng., B 2003, 100, 53.

21. Blumstein, A.; J. Polym. Sci., Part A: Gen. Pap. 1965, 3, 2665.

22. Vahabi, H.; Lin, Q.; Vagner, C.; Cochez, M.; Ferriol, M.; Laheurte, P.; Polym. Degrad. Stab. 2016, 124, 60.

23. Orhan, T.; Isitman, N. A.; Hacaloglu, J.; Kaynak, C.; Polym. Degrad. Stab. 2012, 97, 273.

24. Alexandre, M.; Dubois, P.; Mater. Sci. Eng., R 2000, $28,1$.

25. Laachachi, A.; Leroy, E.; Cochez, M.; Ferriol, M.; Leroy, E.; Lopez Cuesta, J. M.; Polym. Degrad. Stab. 2005, 89, 344.

26. Adams, J. M.; Appl. Clay Sci. 1987, 2, 309.

27. Ugochukwu, U. C.; Jones, M. D.; Head, I. M.; Manning, D. A. C.; Fialips, C. I.; Int. Biodeterior. Biodegrad. 2014, 88, 185.

28. Tahir, S. S.; Rauf, N.; Chemosphere 2006, 63, 1842.

29. Habibi, D.; Marvi, O.; Catal. Commun. 2007, 8, 127.

30. Rocha, R. F.; Rosatto, S. S.; Bruns, R. E.; Kubota, L. T.; J. Electroanal. Chem. 1997, 433, 73.

31. Cota, F. D. P.; Panzera, T. H.; Schiavon, M. A.; Christoforo, A. L.; Borges, P. H. R.; Bowen, C.; Scarpa, F.; Mater. Res. 2012, $15,573$.

32. Lopes, W. L.; Santelli, R. E.; Oliveira, E. P.; de Carvalho, M. F. B.; Bezerra, M. A.; Talanta 2009, 79, 1276.

33. Acharya, G.; Lee, C. H.; Lee, Y.; PLoS One 2012, 7, e43100.

34. Gajra, B.; Pandya, S. S.; Singh, S.; Rabari, H. A.; J. Drug Delivery 2014, 2014, 1.

35. Origin, OriginLab: Northampton, USA, 2013.

36. Statistica, Data Analysis Software System; Statsoft: Tulsa, USA, 2001.

37. Kashiwagi, T.; Hirata, T.; Brown, J. E.; Macromolecules 1985 , $18,131$.

38. Kashiwagi, T.; Morgan, A. B.; Antonucci, J. M.; VanLandingham, M. R.; Harris, R. H.; Awad, W. H.; Shields, J. R.; J. Appl. Polym. Sci. 2003, 89, 2072.

39. Sarmento, V. H. V.; Schiavetto, M. G.; Hammer, P.; Benedetti, A. V.; Fugivara, C. S.; Suegama, P. H.; Pulcinelli, S. H.; Santilli, C. V.; Surf. Coat. Technol. 2010, 204, 2689.

40. Cacioli, P.; Moad, G.; Rizzardo, E.; Serelis, A. K.; Solomon, D. H.; Polym. Bull. 1984, 11, 325. 
41. Holland, B. J.; Hay, J. N.; Polymer 2001, 42, 4825.

42. Teófilo, R. F.; Ferreira, M. M. C.; Quim. Nova 2006, 29, 338.

43. de Barros Neto, B.; Scarminio, I. S.; Bruns, R. E.; Como Fazer Experimentos - Pesquisa e Desenvolvimento na Ciência e na Indústria, $3^{\mathrm{a}}$ ed.; Editora da Unicamp: Campinas, Brasil, 2003.

44. Guilhen, S. N.; Pires, M. A. F.; Dantas, E. S. K.; Xavier, F. V.; Quim. Nova 2010, 33, 1285.
45. Bieseki, L.; Treichel, H.; Araujo, A. S.; Pergher, S. B. C.; Appl. Clay Sci. 2013, 85, 46.

46. Namouchi, F.; Smaoui, H.; Farouti, N.; Zerrouki, C.; Guermazi, H.; Bonnet, B. B.; J. Alloys Compd. 2009, 469, 197.

Submitted: May 15, 2017 Published online: November 13, 2017 